\title{
Epidemiology of Influenza Virus Reinfection: A Retrospective Analysis of a Nine-year Influenza Surveillance Data
}

\section{Jing Wang}

Guangxi Zhuang Autonomous Region Center for Disease Control and Prevention

\section{Lina Jiang}

Guangxi Zhuang Autonomous Region Center for Disease Control and Prevention

\section{Yunan Xu}

Duke University

\section{Weitao He}

Guangxi Center for Disease Control and Prevention

\section{Chao Zhang}

Guangxi Center for Disease Control and Prevention

\section{Fuyin Bi}

Guangxi Center for Disease Control and Prevention

\section{Yi Tan}

Guangxi Center for Disease Control and Prevention

Chuanyi Ning ( $\sim$ ningchuanyi@126.com )

Guangxi Medical University https://orcid.org/0000-0002-8748-2780

\section{Research Article}

Keywords: Orthomyxoviridae, Epidemiology, Influenza virus, Reinfection, Recurrence

Posted Date: October 5th, 2020

DOI: https://doi.org/10.21203/rs.3.rs-81005/v1

License: (c) (1) This work is licensed under a Creative Commons Attribution 4.0 International License. Read Full License 


\section{Abstract}

\section{Background}

Epidemiological characteristics profile of the reinfection of the influenza virus has not been well described.

\section{Methods}

Our study estimated the reinfection rate using nine-year influenza surveillance data and further examined the characteristics associated with the reinfection.

Results

A total of $53,605.6$ person-months and the median time of 8.7 months were observed for reinfection. The cumulative reinfection incidence was $2 \%$ at 6 months, $4 \%$ at 12 months, $5 \%$ at 24 months, and $7 \%$ after 59 months. Living in the rural area ( $\mathrm{HR}=1.37$ [95\% Cl 1.29-1.45]), and age $\leq 6$ years ( $\mathrm{HR}=11.43[95 \% \mathrm{Cl}$ 9.47-13.80]) were independent risk factors associated with influenza reinfection.

\section{Conclusions}

Our findings indicate that the reinfection of the influenza virus in Guangxi independently and positively associated with the rural area and younger age. The unusually high frequency of reinfection points to a need for further prospective longitudinal studies to better investigate sufficient impact on the development of broadly protective or universal vaccines.

\section{Background}

Influenza is an acute viral infection of the respiratory tract and yearly seasonal influenza epidemics are associated with excess morbidity and mortality. The World Health Organization (WHO) provides an estimate that influenza infections annually affect about $5-10 \%$ of adults and $20-30 \%$ of children (WHO, https://www.who.int/ith/diseases/influenza_seasonal/en/) and contribute to approximately 294,000518,000 respiratory deaths globally [1]. Annual influenza vaccination is recommended as an effective measure to prevent seasonal influenza infections, especially among susceptible individuals including older people and children. Studies estimate that the influenza vaccination can prevent about $59 \%(95 \% \mathrm{Cl}$ (confidence interval) 51-66\%) of laboratory-confirmed influenza [2], and when the vaccine strains and circulating strains match well, vaccination can reduce influenza-like-illness (ILI) visits by $42 \%$ (95\% $\mathrm{Cl} 9$ $63 \%$ ) [3]. However, the effectiveness of influenza vaccines varies from season to season depending on a variety of factors, including age and health status of the recipients, previous exposure to influenza viruses, and the matching degree of circulating virus and strains included in the vaccine.

Several studies have already reported reinfections with the same type or subtype of influenza viruses in humans [4-6]. It was estimated that $3-25 \%$ of children experienced reinfections with influenza B 
depending on the influenza seasons [5]. Another study reported that about $32 \%$ of patients living in a remote island experienced two attacks with influenza A (H3N2) virus [6]. However, most of these studies were established based on a case report, which only focuses on a specific population with a small sample size. It is difficult to systematically analyze the epidemiological characteristics of the influenza reinfections in a population-based. As known, influenza infections are more likely to affect some specific populations, such as child and older people, and more likely to occur in a certain season, typically in fall and winter [7]. Understanding the epidemiological features of the re-infected population would provide useful information for future prevention of seasonal influenza.

China has developed a national influenza surveillance and response system to improve early response to the influenza virus with pandemic potential. All newly diagnosed influenza cases were required to be reported via the National Notifiable Infectious Disease Reporting Information System (NIDRIS) within 24 hours after diagnosis. The establishment of this system provides an opportunity to capture influenza virus reinfections in a diverse population and further analyze the epidemiological characteristics. In this study, we identified demographic characteristics associated with influenza reinfection using data abstracted from NIDRIS. The findings of this study will advance our understanding of characteristics that may increase the risk of reinfections and inform the prevention measures to decrease influenza burden.

\section{Materials And Methods}

\section{Data Source}

Data of this study included all influenza cases of Guangxi China from January 2011 to December 2019 recorded in NIDRIS. The NIDRIS database encompasses data on demographics including patients' name, the name of either of the patient's guardians (if age $<18$ years), national identification number, sex, date of birth, age, contact telephone number, living address, and diagnosis classification (clinically diagnosed cases or laboratory-confirmed cases), and date of illness onset and diagnosis, and virus serotype for those laboratory-confirmed cases. Clinically diagnosed cases and laboratory-confirmed cases were defined according to influenza diagnosis and treatment protocol designed by the National Health Commission of the People's Republic of China [8]. Patients were defined as laboratory-confirmed cases if the pharyngeal swabs were positive RT-PCR results tested by the local CDC. The study was approved by the institutional review board of the Guangxi Center for Disease Control and Prevention.

\section{Definition of influenza reinfections}

With the approval of Guangxi Center for Disease Control and Prevention, we extracted data on patients' names, the name of either of the patient's parents, national identification number, date of birth, contact telephone number, and living address from NIDRIS. We matched their personal information to identify reinfection episodes. The process of defining influenza reinfections was shown in Figure 1. A total of 150,212 patients with 154,732 episodes were abstracted from NIDRIS. A total of 4710 potential reinfection cases were first identified based on one of the following criteria: 1) having the same name and national identification number; or 2) having the same name and contact telephone number; or 3) having 
the same name, birth date, and living address; or 4) having the same name, guardians' name, and birth date; or 5) having the same name, guardians' name, and living address.

Taking into account the incubation period and duration of symptoms, independent attacks were defined with the two infections with >35-day interval, combined with the longest incubation period of influenza reported ( 7 days) and the longest duration of symptoms onset ( 28 days). Patients who experienced $\geq 2$ independent attacks were defined as influenza reinfection cases. This 35-day criterion was used to define both clinically diagnosed reinfections and laboratory-confirmed reinfections. Finally, we identified 4,007 patients who had influenza reinfection, and 237 cases underwent laboratory tests. Among them, 49 underwent twice laboratory tests that confirmed the types of influenza viruses (i.e. types A and B).

\section{Statistical analysis}

Comparisons of characteristics between patients who had one infection and reinfection were performed using the chi-square test for categorical variables and Mann-Whitney U-Test for continuous variables not following a normal distribution. Kaplan-Meier estimate and log-rank tests were used to assess the proportion of influenza reinfections overtime after their first infections. Cox proportional hazards models were used to explore the characteristics associated with reinfection. All patients who experienced twice laboratory-confirmed test were categorized to 4 groups based on the types of the influenza viruses infected: 1 ) both type $A, 2$ ) both type $B, 3$ ) type A followed by type $B$, and 4 ) type B followed by type A. All analyses were conducted using $R$ Project (vision 3.6.3) and $p \leq 0.05$ in 2-tailed was considered statistically significant.

\section{Results}

Table 1 shows patients characteristics. The median age at the first infection was 4.5 (IQR=2.0-7.5) years. About half of the patients were males (56.1\%) and living in the rural area (52.6\%). Among the patients who had reinfection, $10.0 \%$ infected three times, and $2.6 \%$ infected four times or more. Compared with the patients without reinfection, those with reinfection were younger and more likely to live in a rural area $(p<0.001)$. Figure 2 shows the influenza seasonality across 2011-2019. For the entire sample, while influenza viruses circulated year-round, influenza season generally occurred in the fall and winter. Most of the time influenza activity peaked in fall and winter, but activity could last as late as spring. The incidence of influenza infection increased in recent years, particularly after 2018. The patterns were similar for the patients with reinfection and those with laboratory-confirmed reinfection.

During the observation period, the patients contributed a total of 53,605.6 person-month and a median of 11.1 months (IQR 5.3-19.5) after their first incidence. The recurrent episode occurred 1.2-96.1 months (median 8.7) between two consecutive onsets. Specifically, the cumulative reinfection incidence was $2 \%$ at 6 months, $4 \%$ at 12 months, $5 \%$ at 24 months, and $7 \%$ after 59 months. However, in the lower age group (age $\leq 6$ years), the rate reached $4 \%$ at 6 months, $7 \%$ at 12 months, remained $12 \%$ after 73 months; for the teenagers (7-18 years), the rate was $1 \%$ at 7 months, $2 \%$ at 12 months, reached $5 \%$ at 45 months; and for the elder patients ( $>18$ years), the rate still maintained $1 \%$ until the end of the observation period 
(107 months) (STable). The probability rate in urban and rural area at 12 months, 24 months and 36 months was $3 \%$ vs. $5 \%, 4 \%$ vs. $6 \%, 6 \%$ vs. $7 \%$, respectively. Multiple Cox regression analysis indicated that living in the rural area (hazard ratio [HR]=1.37 [95\% Cl 1.29-1.45]), age $\leq 6$ year (HR=11.43 [95\% Cl 9.4713.80]), and age between 7 and 18 years ( $\mathrm{HR}=3.57$ [95\% $\mathrm{Cl} 2.95-4.33]$ ) were independent risk factors associated with influenza reinfection (Figure 3 ). The survival rate was significantly different across age groups of $<=6,7-18$, and $>18$ years $(p<0.001)$ and was different between urban residence and rural residence $(p<0.001)$.

Of the 237 patients with recurrent laboratory-confirmed influenza, 219 patients (92.4\%) had 2 episodes and 18 patients $(8.0 \%)$ had $\geq 2$ episodes. Among 49 patients experiencing twice laboratory tests, 12 was infected with influenza type $A$ twice, 5 infected with influenza type B twice, 14 infected type $A$ followed by type $B$, and 18 infected with type $B$ followed by type $A$. The interval between two consecutive laboratoryconfirmed episodes of the four groups differed $(p=0.148)$, as the maximum was 72.9 months, and the minimum was 1.2 months (Table 2).

\section{Discussion}

Although several studies reported recurrent influenza, most of that was case-report $[5,6,9]$, our results showed reinfection of influenza is not a rare phenomenon. We found that a total of 4,007 patients $(8,527$ episodes) with probable recurrence influenza in Guangxi among 2011-2019. Recurrence of influenza occurred 1.2-96.1 months after the primary infection and reached $7 \%$ at 59 months in our study. Living in the rural area and younger age were independent risk factors associated with influenza virus reinfection. During the observational period, $2.7 \%$ of people experienced influenza reinfection. Living in a rural area and $<18$-year was associated with influenza virus reinfection.

The results of this study showed that the influenza reinfection episodes primarily appeared after 2018, which was similar to the patterns for the entire sample. The consistent trend between infection and reinfection means more infection will undoubtedly lead to an increase in recurrence. Our finding that influenza cases surged in 2019 is consistent with the previous studies that have reported in other countries [10]. One possible reason is that the proportion of a variant with the three-amino-acid deletion was rising, which were antigenically different from the vaccine strain for the 2018-2019 season [11]. Another reason may be due to a rapid increase in the relevant genetic diversity of the influenza A (H1N1) pdm09 virus between 2018-2019 [12].

It seems reasonable that most individuals are probably relatively protected from reinfection with the same or different influenza strains and subtypes for several months [13]. Previous studies showed that vaccination-induced protection gradually waned after $6-12$ months $[14,15]$. Our study suggests that the influenza reinfection occurred at an average of 8.7 months after the previous infection. The influenza reinfection may be due to the possibility of a suboptimal immune response after the initial natural infection, which led to the failure to protect the reinfection. The study has shown that individuals could be re-infected by the same stain during the multi-wave outbreaks $[6,16]$. A recent experiment study reported 
that individuals could be re-infected by the identical A (H1N1) pdm09 influenza virus about 1 year after initial infection, and speculated that it could be due to lacking protective immunity induced by the previous infection [4]. Likewise, other studies reported that short-interval sequential infections could be a possible explanation for the multi-wave epidemic of $A(H 3 N 2)[6,17]$.

Extrinsic properties, such as demographics and environment, have also been associated with influenza reinfection [18]. Consistent with previous studies that have suggested high risks of influenza reinfection among children and juniors [5], we found less than 18 years old was an independent risk factor associated with reinfection. Children might be more vulnerable to be attacked by the influenza virus due to immature immunity or immunodeficiency. On the other hand, in adults protection against A (H3N2) lasted longer than that in children [19], and antibody response induced by one strain was more likely to protect against another related-strains [20,21], which might reduce the risk of reinfection in adults. In addition, our study suggests that people living in rural areas were more likely to get re-infected, which is consistent with previous studies that showed that rural residences presented a risk factor with respiratory disease [22]. The high risk of reinfection might be attributed to less access to health education and host behavior, such as higher rates of tobacco use, physical inactivity, lower rates of fruit and vegetable intake [23].

Previous studies have reported antibody-dependent enhancement in some communicable diseases, such as dengue virus or other coronaviruses of the SARS type, which increased the transmissibility of the previous infection to the new infections $[24,25]$. Thus, further research is needed to explore whether primary influenza infection reduces or increases the susceptibility of reinfection or transmission of reinfection, increasing the probability of reinfection. In addition, a study showed that patients with reinfection had relatively milder symptoms compared with their first infection [26]. We did not examine the association due to a lack of data about the severity of symptoms. Thus, further studies are needed to further testify whether reinfection could aggravate or ease the progress of the illness.

Our study has several limitations. First of all, most recurrent influenza episodes occurred in recent two years 2018-2019, resulting in the observation periods were not sufficient. This may raise concerns that the burden of recurrence influenza we found was underestimated. Meanwhile, this made a little difficult to draft the conclude that influenza reinfection shared a similar seasonal pattern [27]. In addition, the sample size of patients receiving laboratory tests is too small, which may result in insufficient statistical power and impact the accuracy of the results. Also, we could not describe the features of patients with specific influenza classification strains due to a lack of nuclear-acid testing results. Last but not least, lacking immunization records may underestimate the cumulative probability rate of influenza recurrence.

\section{Conclusions}

In conclusion, analyzing the nine-year surveillance data, our study demonstrates a high burden of influenza reinfection especially for people less than 18 years and living in a rural area. It is essential to expand the detection of pathogens to further clarify the probability of influenza infection and the 
reinfection by different subtypes of influenza. This study also advances our understanding of the crossimmunity effects between different subtypes, providing scientific evidence supporting the development of vaccination strategies. Furthermore, clinical and basic studies are warranted to assess the immune response to influenza reinfection and whether it will aggravate the severity of the disease.

\section{Abbreviations}

$\mathrm{Cl}$, confidential interval; HR, Hazard Ratio; NIDRIS, National Notifiable Infectious Disease Reporting Information System; RT-PCR, Reverse Transcription-Polymerase Chain Reaction; SARS, Severe Acute Respiratory Syndrome.

\section{Declarations}

\section{Ethics approval and consent to participate}

The study was approved by the institutional review board of the Guangxi Center for Disease Control and Prevention.

\section{Consent for publication}

Not applicable.

\section{Availability of data and materials}

All data are available in the manuscript.

\section{Competing interests}

The authors declare that they have no known competing financial interests or personal relationships that could have appeared to influence the work reported in this paper.

\section{Funding}

This work was supported by Guangxi Natural Science Foundation (2017JJA140773y) and Natural Science Foundation of China (81803295).

\section{Authorship contribution statement}

Chuanyi Ning: Formal analysis, Supervision. Yi Tan: Writing - review \& editing, Supervision.

Jing Wang, Lina Jiang and Yunan Xu: Conceptualization, Methodology, Writing - original draft. Chao Zhang, Weitao He and Fuyin Bi: Data curation.

\section{Acknowledgments}


We would like to thank all staffs in the local Center for Disease Control and Prevention (CDC) and ILI Sentinel hospital in Guangxi for providing assistance with data collection. We also thank Dr. Hao Chen from Oak Ridge Institute of Science and Education, Oak Ridge, TN, USA for critical review of our manuscript.

\section{Author information}

Guangxi Center for Disease Prevention and Control, Nanning, Guangxi, China Jing Wang, Lina Jiang, Weitao He, Fuyin Bi, Chao Zhang and Yi Tan.

Duke University, Durham, North Carolina, USA

Yunan Xu.

Guangxi Medical University, Nanning, Guangxi, China

Chuanyi Ning.

Address for correspondence: Chuanyi Ning, Guangxi Medical University, 8 Shuangyong Road, Guangxi 530021, China; email: ningchuanyi@126.com/ningchuanyi@gxmu.edu.cn. Yi Tan, PhD, Guangxi Center for Disease Prevention and Control, 18 Jinzhou Road, Nanning, Guangxi 530028, China; email: jcs@gxcdc.com.

\section{References}

1. Paget J, Spreeuwenberg P, Charu V, Taylor RJ, Iuliano AD, Bresee J, Simonsen L, Viboud C, Global Seasonal Influenza-associated Mortality Collaborator N, Teams* GLC: Global mortality associated with seasonal influenza epidemics: New burden estimates and predictors from the GLaMOR Project. J Glob Health 2019, 9(2):020421.

2. Osterholm MT, Kelley NS, Sommer A, Belongia EA: Efficacy and effectiveness of influenza vaccines: a systematic review and meta-analysis. Lancet Infect Dis 2012, 12(1):36-44.

3. Demicheli V, Jefferson T, Ferroni E, Rivetti A, Di Pietrantonj C: Vaccines for preventing influenza in healthy adults. Cochrane Database Syst Rev 2018, 2:CD001269.

4. Memoli MJ, Han A, Walters KA, Czajkowski L, Reed S, Athota R, Angela Rosas L, Cervantes-Medina A, Park JK, Morens DM et al: Influenza A Reinfection in Sequential Human Challenge: Implications for Protective Immunity and "Universal" Vaccine Development. Clin Infect Dis 2020, 70(5):748-753.

5. Nakajima S, Nishikawa F, Nakamura K, Nakao H, Nakajima K: Reinfection with influenza B virus in children: analysis of the reinfection influenza B viruses. Epidemiol Infect 1994, 113(1):103-112.

6. Camacho A, Ballesteros S, Graham AL, Carrat F, Ratmann O, Cazelles B: Explaining rapid reinfections in multiple-wave influenza outbreaks: Tristan da Cunha 1971 epidemic as a case study. Proc Biol Sci 2011, 278(1725):3635-3643. 
7. Uyeki TM: Influenza. Ann Intern Med 2017, 167(5):ITC33-ITC48.

8. Zhong NS, Li YM, Yang ZF, Wang C, Liu YN, Li XW, Shu YL, Wang GF, Gao ZC, Deng GH et al: Chinese guidelines for diagnosis and treatment of influenza (2011). J Thorac Dis 2011, 3(4):274-289.

9. Nakajima S, Nishikawa F, Nakamura K, Nakajima K: Analysis of influenza A virus reinfection in children in Japan during 1983-91. Epidemiol Infect 1995, 115(3):591-601.

10. Sullivan SG, Arriola CS, Bocacao J, Burgos P, Bustos P, Carville KS, Cheng AC, Chilver MB, Cohen C, Deng YM et al: Heterogeneity in influenza seasonality and vaccine effectiveness in Australia, Chile, New Zealand and South Africa: early estimates of the 2019 influenza season. Euro Surveill 2019, 24(45).

11. Kato-Miyashita S, Sakai-Tagawa Y, Yamashita M, Iwatsuki-Horimoto K, Ito M, Tokita A, Hagiwara H, Izumida N, Nishino T, Wada N et al: Antigenic variants of influenza B viruses isolated in Japan during the 2017-2018 and 2018-2019 influenza seasons. Influenza Other Respir Viruses 2020, 14(3):311319.

12. Ma Y, Liu K, Yin Y, Qin J, Zhou YH, Yang J, Li S, Poon LLM, Zhang C: The Phylodynamics of Seasonal Influenza A/H1N1pdm Virus in China Between 2009 and 2019. Front Microbiol 2020, 11:735.

13. Webster RG, Bean WJ, Gorman OT, Chambers TM, Kawaoka Y: Evolution and ecology of influenza A viruses. Microbiol Rev 1992, 56(1):152-179.

14. Jacobson RM, Grill DE, Oberg AL, Tosh PK, Ovsyannikova IG, Poland GA: Profiles of influenza A/H1N1 vaccine response using hemagglutination-inhibition titers. Hum Vaccin Immunother 2015, 11(4):961-969.

15. Petrie JG, Ohmit SE, Johnson E, Truscon R, Monto AS: Persistence of Antibodies to Influenza Hemagglutinin and Neuraminidase Following One or Two Years of Influenza Vaccination. $J$ Infect Dis 2015, 212(12):1914-1922.

16. Gomes MG, White LJ, Medley GF: Infection, reinfection, and vaccination under suboptimal immune protection: epidemiological perspectives. J Theor Bio/ 2004, 228(4):539-549.

17. Camacho A, Cazelles B: Does homologous reinfection drive multiple-wave influenza outbreaks? Accounting for immunodynamics in epidemiological models. Epidemics 2013, 5(4):187-196.

18. Boelle PY: The perpetuation and epidemic recurrence of communicable diseases in human populations. CR Bio/ 2007, 330(4):356-363.

19. Ranjeva S, Subramanian R, Fang VJ, Leung GM, Ip DKM, Perera R, Peiris JSM, Cowling BJ, Cobey S: Age-specific differences in the dynamics of protective immunity to influenza. Nat Commun 2019, 10(1):1660.

20. Hancock K, Veguilla V, Lu X, Zhong W, Butler EN, Sun H, Liu F, Dong L, DeVos JR, Gargiullo PM et al: Cross-reactive antibody responses to the 2009 pandemic $\mathrm{H} 1 \mathrm{~N} 1$ influenza virus. N Engl J Med 2009, 361(20):1945-1952.

21. Yu X, Tsibane T, McGraw PA, House FS, Keefer CJ, Hicar MD, Tumpey TM, Pappas C, Perrone LA, Martinez $O$ et al: Neutralizing antibodies derived from the B cells of 1918 influenza pandemic survivors. Nature 2008, 455(7212):532-536. 
22. Raju S, Keet CA, Paulin LM, Matsui EC, Peng RD, Hansel NN, McCormack MC: Rural Residence and Poverty Are Independent Risk Factors for Chronic Obstructive Pulmonary Disease in the United States. Am J Respir Crit Care Med 2019, 199(8):961-969.

23. Harris JK, Beatty K, Leider JP, Knudson A, Anderson BL, Meit M: The Double Disparity Facing Rural Local Health Departments. Annu Rev Public Health 2016, 37:167-184.

24. Wearing $\mathrm{HJ}$, Rohani P: Ecological and immunological determinants of dengue epidemics. Proc Natl Acad Sci U S A 2006, 103(31):11802-11807.

25. Yang ZY, Werner HC, Kong WP, Leung K, Traggiai E, Lanzavecchia A, Nabel GJ: Evasion of antibody neutralization in emerging severe acute respiratory syndrome coronaviruses. Proc Natl Acad Sci U S A 2005, 102(3):797-801.

26. Trakulsrichai S, Watcharananan SP, Chantratita W: Influenza A (H1N1) 2009 reinfection in Thailand. J Infect Public Health 2012, 5(2):211-214.

27. Flahault A, Dias-Ferrao V, Chaberty P, Esteves K, Valleron AJ, Lavanchy D: FluNet as a tool for global monitoring of influenza on the Web. JAMA 1998, 280(15):1330-1332.

\section{Tables}

Table 1 Demographic characteristic of patients without or with recurrent influenza in Guangxi, 2011-2019 


\begin{tabular}{|c|c|c|c|c|}
\hline & $\begin{array}{l}\text { Patients with } 1 \\
\text { episode } \\
(\mathrm{N}=146,205)\end{array}$ & $\begin{array}{l}\text { Patients with } \geq 2 \\
\text { episodes } \\
(\mathrm{N}=4,007)\end{array}$ & $\begin{array}{l}\text { Statistics } \\
\text { (df) }\end{array}$ & $\begin{array}{l}\mathrm{p} \text { - } \\
\text { value }\end{array}$ \\
\hline Sex, n (\%) & & & $X^{2}(1)=1.320$ & 0.251 \\
\hline Male & $80,613(55.1)$ & $2,246(56.1)$ & & \\
\hline Female & $65,592(44.9)$ & $1,761(43.9)$ & & \\
\hline Residence, n (\%) & & & $\begin{array}{l}X^{2}(1) \\
=22.348\end{array}$ & $<0.001$ \\
\hline Rural & 71,383 (48.8) & 2,108 (52.6) & & \\
\hline Unban & $74,822(51.2)$ & $1,899(47.4)$ & & \\
\hline Age (yr), n (\%) & & & $\begin{array}{l}X^{2}(4) \\
=2293.171\end{array}$ & $<0.001$ \\
\hline$\leq 1$ & $12,696(8.7)$ & $964(24.1)$ & & \\
\hline $2-6$ & $38,851(26.6)$ & $1,820(45.4)$ & & \\
\hline 7-18 & $76,131(52.1)$ & $1,128(28.2)$ & & \\
\hline $19-59$ & $15,377(10.5)$ & $77(1.9)$ & & \\
\hline$\geq 60$ & $3,150(2.1)$ & $18(0.4)$ & & \\
\hline Median (IQR) & $8.2(4.3-13.9)$ & $4.5(2.0-7.5)$ & $Z=-42.819$ & $<0.01$ \\
\hline \multicolumn{5}{|c|}{$\begin{array}{l}\text { Frequency of infection } \\
\text { episode, } \mathrm{n}(\%)\end{array}$} \\
\hline 2 & - & 4,007 (100.0) & - & - \\
\hline 3 & - & $400(10.0)$ & & \\
\hline$\geq 4$ & - & $105(2.6)$ & & \\
\hline
\end{tabular}

Note: df, degree of freedom. yr, year. IQR, Inter Quartile Range.

Table 2 Demographic characteristics of patients with recurrent laboratory-confirmed influenza in Guangxi, 2011-2019 


\begin{tabular}{|c|c|c|c|c|}
\hline & \multirow{2}{*}{$\begin{array}{l}\text { Reinfection after } \\
\text { influenza A with } \\
\text { influenza A } \\
(\mathrm{N}=12)\end{array}$} & \multirow{2}{*}{$\begin{array}{l}\text { Reinfection after } \\
\text { influenza A with } \\
\text { influenza B } \\
(\mathrm{N}=14)\end{array}$} & \multirow{2}{*}{$\begin{array}{l}\text { Reinfection after } \\
\text { influenza B with } \\
\text { influenza A } \\
(\mathrm{N}=18)\end{array}$} & \multirow{2}{*}{$\begin{array}{l}\text { Reinfection after } \\
\text { influenza B with } \\
\text { influenza B } \\
(\mathrm{N}=5)\end{array}$} \\
\hline & & & & \\
\hline \multicolumn{5}{|l|}{ Sex, n (\%) } \\
\hline Male & $7(58.3)$ & $10(71.4)$ & $10(55.6)$ & $3(60.0)$ \\
\hline \multicolumn{5}{|l|}{ Residence, n (\%) } \\
\hline Rural & $3(25.0)$ & $3(21.4)$ & $7(38.9)$ & $2(40.0)$ \\
\hline \multicolumn{5}{|c|}{$\begin{array}{l}\text { Age at first episode } \\
(\mathrm{yr}), \mathrm{n}(\%)\end{array}$} \\
\hline$\leq 1$ & $2(16.7)$ & $2(14.3)$ & $2(11.1)$ & 0 \\
\hline $2-6$ & $6(50.0)$ & $5(35.7)$ & $13(72.2)$ & $4(80.0)$ \\
\hline $7-18$ & $4(33.3)$ & $6(42.9)$ & $3(16.7)$ & 0 \\
\hline $19-59$ & 0 & $1(7.1)$ & 0 & 0 \\
\hline$\geq 60$ & 0 & 0 & 0 & $1(20.0)$ \\
\hline Median (IQR) & $4.0(2.2-6.9)$ & $6.4(3.9-10.3)$ & $5.2(1.9-6.2)$ & $3.3(2.1-63.9)$ \\
\hline \multicolumn{5}{|l|}{$\begin{array}{l}\text { Interval between } \\
\text { two laboratory- } \\
\text { confirmed (mo) }\end{array}$} \\
\hline Median (range) & $25.1(8.0-64.8)$ & $14.4(3.3-59.0)$ & $12.1(1.2-72.9)$ & $4.7(2.0-28.4)$ \\
\hline
\end{tabular}

Note: yr, year. IQR, Inter Quartile Range. mo, month.

\section{Figures}


154,732 influenza episodes reported in Guangxi, 2011-2019

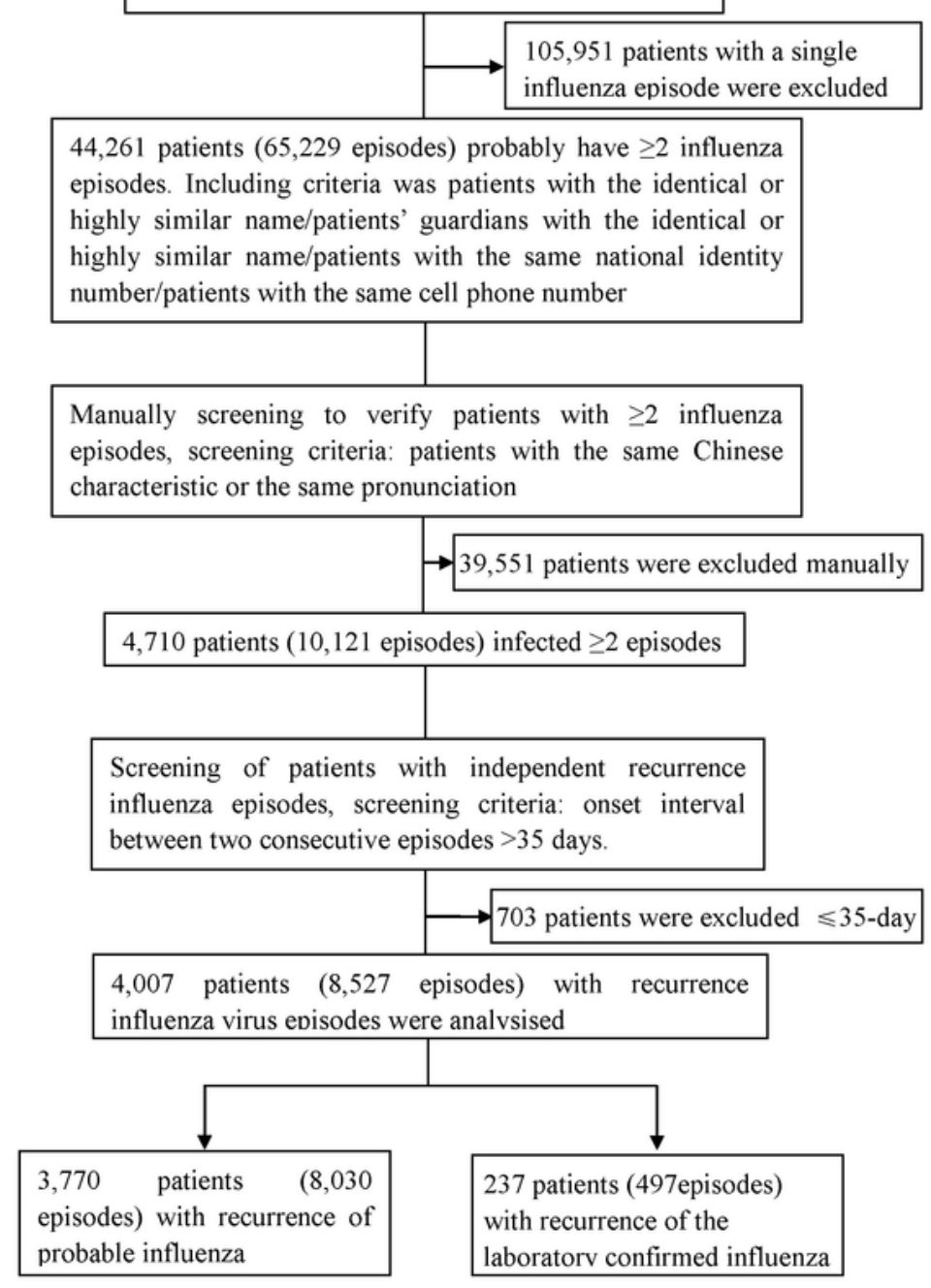

\section{Figure 1}

Flow diagram of selection process for patients with recurrent influenza and laboratory confirmed from NIDRIS in Guangxi, 2011-2019. 

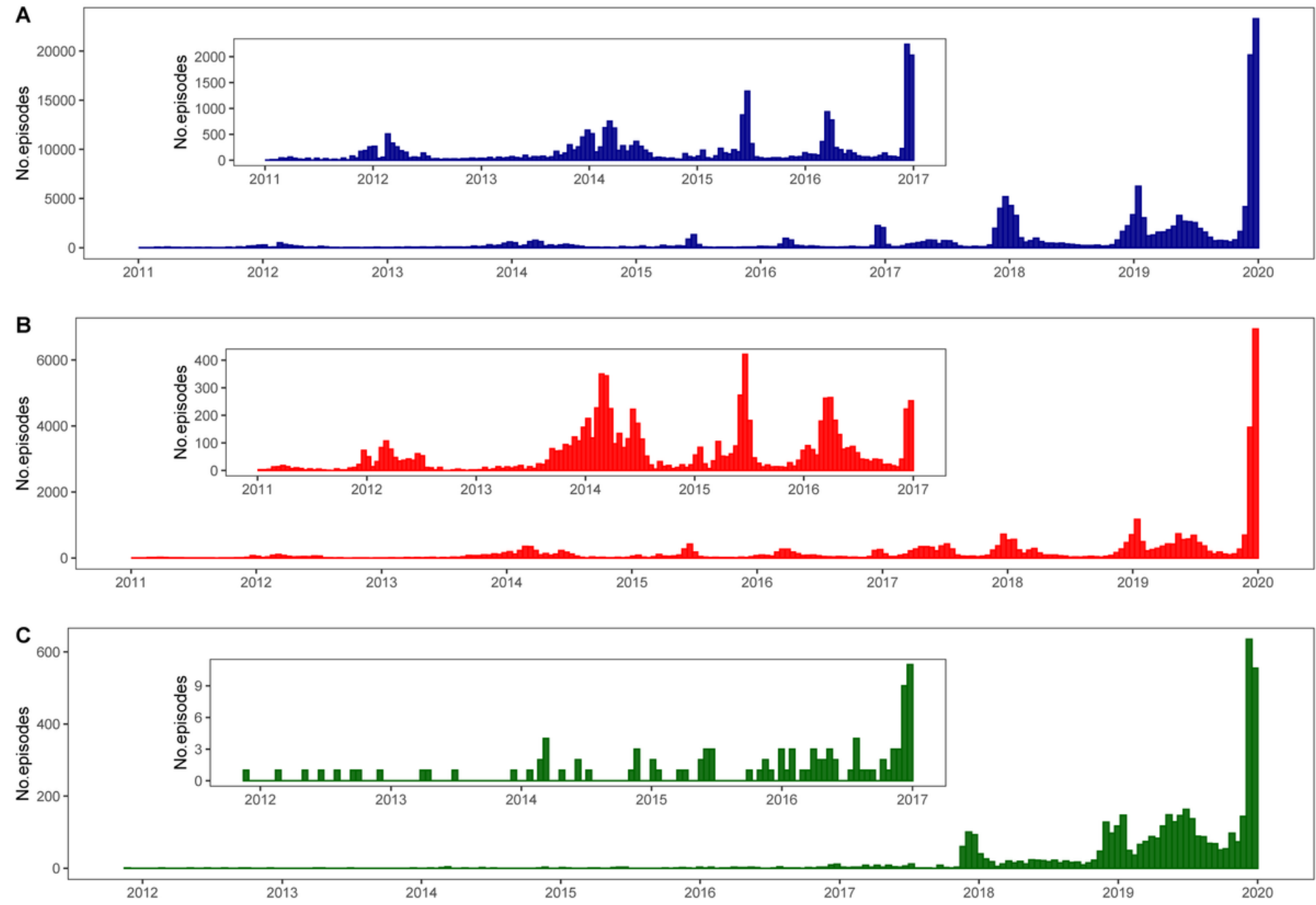

Figure 2

Timeline for outbreak of influenza virus in Guangxi, 2011-2019. A) all influenza cases reported; B) all laboratory-confirmed cases reported; $C$ ) all influenza recurrence cases. The smaller frames above each figures just reduced the vertical from 2011 to 2017 to get a clearer illustration of the trends by time. 
A
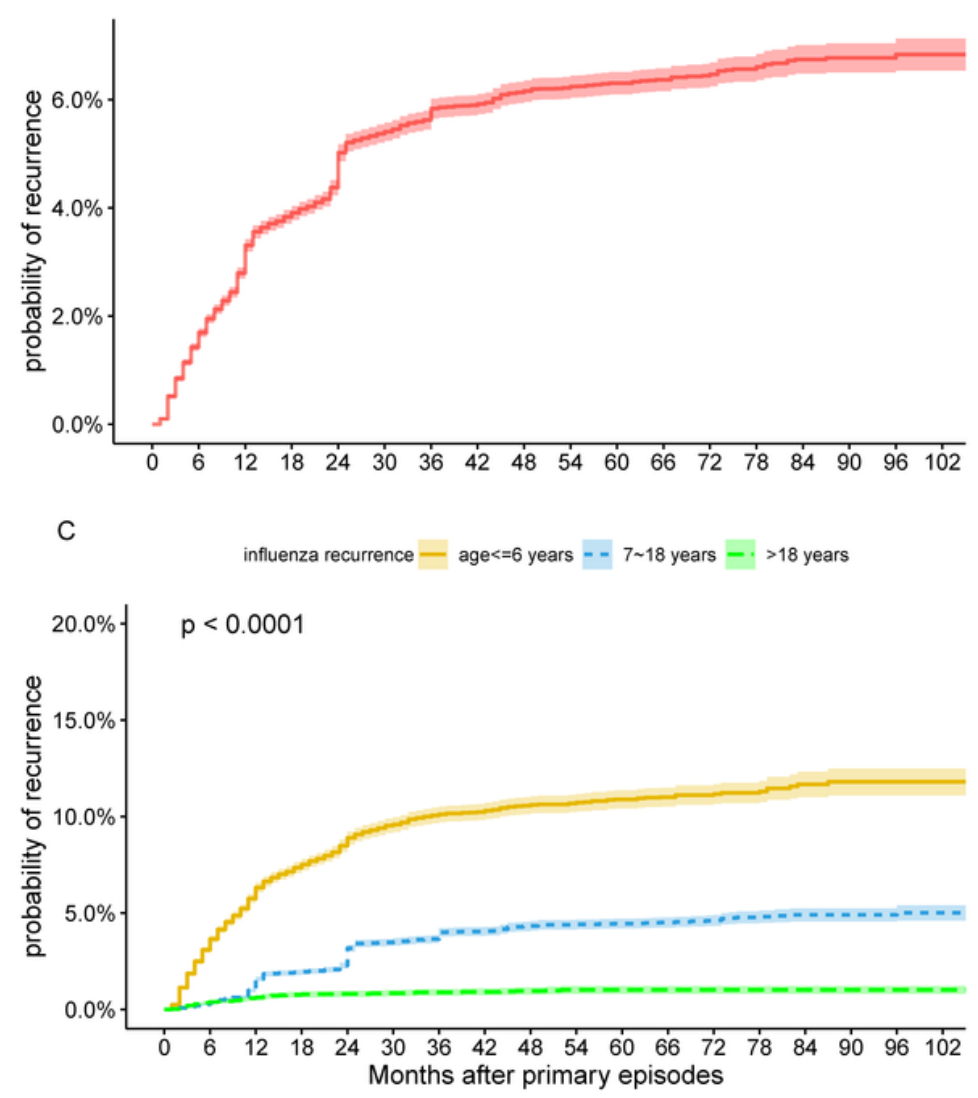

B

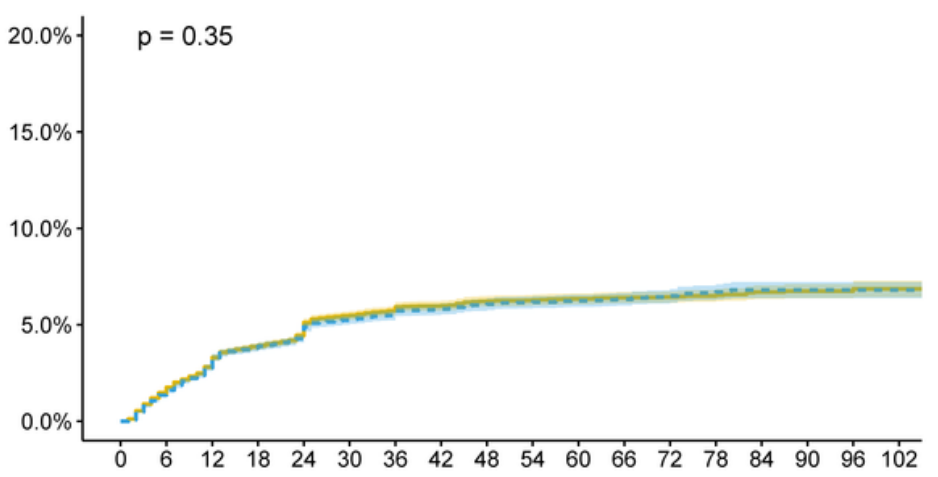

D

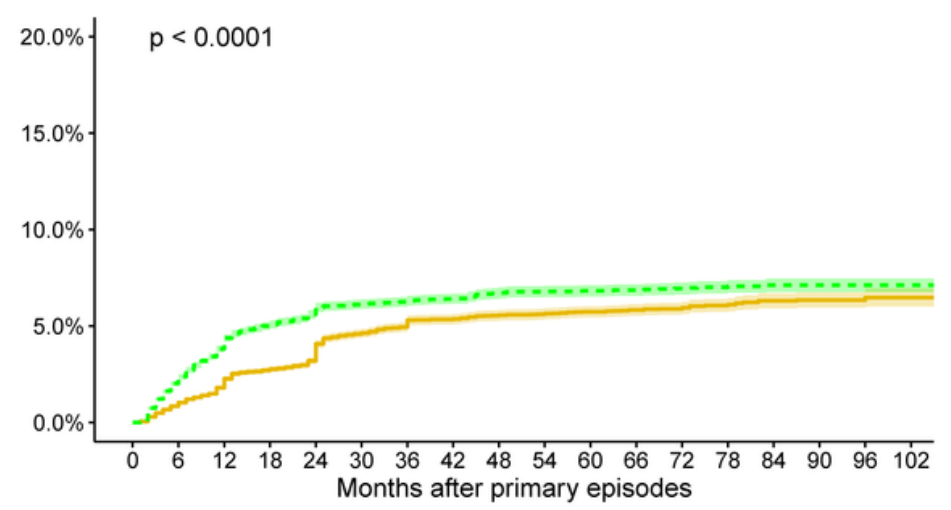

\section{Figure 3}

Kaplan-Meier analysis of survival for influenza recurrence after primary episodes in Guangxi, 2011-2019. A) the cumulative probability of reinfection among all patient with reinfection; B) the cumulative probability of reinfection among patients with different gender; $C$ ) the cumulative probability of reinfection among patients with different age group; D) the cumulative probability of reinfection among patients living in rural and urban. 